
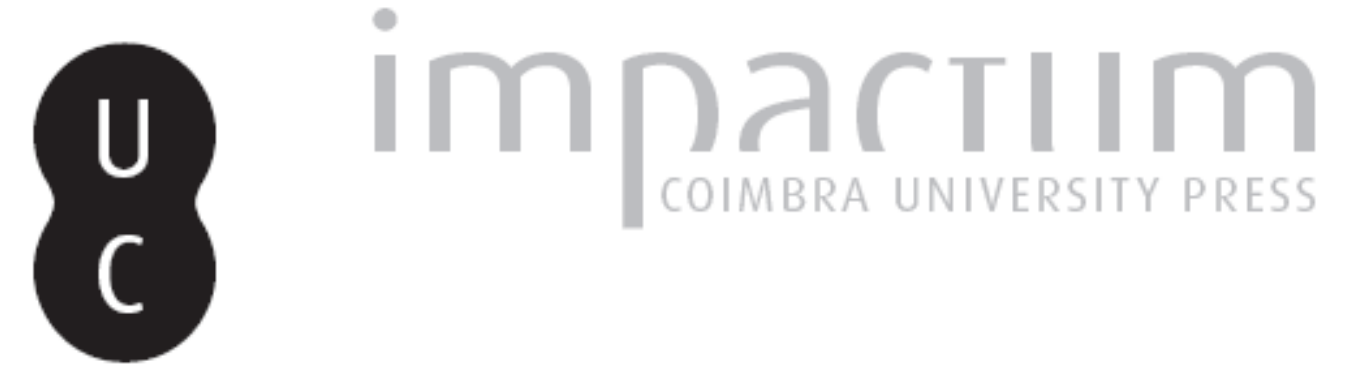

\title{
Vis medicatrix naturae: a água como cura e como bem
}

Autor(es): $\quad$ Osswald, W.

Publicado por: Faculdade de Letras da Universidade de Coimbra, Instituto de História Económica e Social

URL persistente:

URI:http://hdl.handle.net/10316.2/28191

DOI:

DOI:http://dx.doi.org/10.14195/0870-4147_43_14

Accessed : $\quad$ 26-Apr-2023 12:04:44

A navegação consulta e descarregamento dos títulos inseridos nas Bibliotecas Digitais UC Digitalis, UC Pombalina e UC Impactum, pressupõem a aceitação plena e sem reservas dos Termos e Condições de Uso destas Bibliotecas Digitais, disponíveis em https://digitalis.uc.pt/pt-pt/termos.

Conforme exposto nos referidos Termos e Condições de Uso, o descarregamento de títulos de acesso restrito requer uma licença válida de autorização devendo o utilizador aceder ao(s) documento(s) a partir de um endereço de IP da instituição detentora da supramencionada licença.

Ao utilizador é apenas permitido o descarregamento para uso pessoal, pelo que o emprego do(s) título(s) descarregado(s) para outro fim, designadamente comercial, carece de autorização do respetivo autor ou editor da obra.

Na medida em que todas as obras da UC Digitalis se encontram protegidas pelo Código do Direito de Autor e Direitos Conexos e demais legislação aplicável, toda a cópia, parcial ou total, deste documento, nos casos em que é legalmente admitida, deverá conter ou fazer-se acompanhar por este aviso.

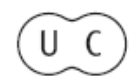





\title{
Vis medicatrix naturae - a água como cura e como bem
}

\author{
W. OSSWALD \\ Professor Catedrático Aposentado da Faculdade de Medicina da Universidade do Porto \\ Detentor da Cátedra UNESCO de Bioética \\ Conselheiro do Instituto de Bioética da Universidade Católica Portuguesa
}

\section{Resumo:}

Neste ensaio, a água é vista do ponto de vista da saúde humana. Uma breve visita à história conduz à elencagem dos usos da água em terapia, com especial menção da hidroterapia (praticada com qualquer água não poluída) e da crenoterapia (realizada em estâncias termais, com recurso à água com características especiais que brota nesse local). São apontados os problemas médicos, sociais e económicos do termalismo, bem como as causas das dificuldades que enfrenta, entre as quais avulta o cepticismo quanto à eficácia da crenoterapia.A este propósito, sublinha-se que, embora não exista uma evidência científica dessa eficácia, vários factores depõem a favor do benefício para a saúde resultante do tratamento termal. Procede-se, finalmente, a uma análise ética das questões suscitadas pela escassez de água e do seu uso, sublinhando-se que se trata aqui de preservar e legar às gerações futuras um bem precioso.

Palavras chave:

Hidroterapia; Crenoterapia; Ética do uso da água; Termalismo.
Abstract:

Water is considered, in this essay, from the point of view of human health. A short visit to its history is followed by a description of the use of water in medical treatment, focusing on hydrotherapy (which uses common, non polluted water) and crenotherapy (used in springs or wells, the water of which shows distinctive chemo-physical characteristics). Medical, social and economic aspects of thermalism, i.e. the complex arising from baths or springs, are briefly discussed. Present day difficulties arise mainly from skepticism concerning the therapeutic efficacy of the springs, but it should be underlined that although there is no scientific evidence of this efficacy, there are many factors that plead for a real benefit. Finally, an ethical evaluation of questions concerning water scarcity and the right to have access to water is presented, concluding with the view that we have to preserve and to bequeath as legacy to future generations a precious commodity.

Keywords:

Hydrotherapy; Therapy in springs; Ethics of the use of water; Springs and welfare. 


\section{Qual água?}

De que água estamos a falar, qual é o líquido que nos interpela e suscita uma reflexão? A água do poeta, por exemplo, materializada numa gota iridescente, trémula refracção na ponta de uma folha de camélia, insegura, fugaz na duração, eterna na canção que a evoca e celebra? Ou a água do químico, que vê ligações de hidrogénio e mede o ângulo médio da ligação H-O-H e triunfantemente anuncia que ele é de $104,5^{\circ}$, o que faz com que a molécula, neutra, assuma a forma polar, e lhe assegura reactividade, capacidade de formar hidratos e espantosa versatilidade. O físico, por seu turno, revela que mesmo a mais plácida e serena água, à superfície de um lago ou no interior de um copo, alberga uma enorme agitação: a incríveis velocidades, as suas moléculas parecem tecer aleatórios desenhos. O mesmo físico nos lembrará que a água é absolutamente original no seu comportamento: está presente na terra sob forma líquida, sólida e gasosa (vapor de água) e quando solidifica torna-se mais leve, ou seja, menos densa, o que não acontece com nenhuma outra substância.

Indispensável à vida, em contínuo ciclo metabólico no organismo humano, importante elemento da alimentação (podemos viver muitos dias sem comer, mas apenas 48-72 horas sem beber) - são factos que o bioquímico e o nutricionista nos recordarão. Já o jurista e o político focarão outros aspectos: o direito à água, a posse de fontes, nascentes, cursos de água, lagos e oceanos, os conflitos a que tem dado origem a disputa acerca desses direitos, dos pequenos dramas rurais (questão dirimida à sacholada, p. ex.) aos graves conflitos internacionais (Israel - Síria - Montes Golan, rio Jordão; Turquia, Iraque, rio Eufrates). A visão do historiador abrangerá, certamente, estes aspectos, mas estende-se bem mais largamente sobre as relações do ser humano com os cursos de água e o grande mar oceano; no seu campo de estudo estarão a superação dos obstáculos fluviais pela construção de pontes, a navegabilidade dos rios e a conquista dos mares, primeiro desafio da infinitude ao "bicho da terra, vil e tão pequeno".

As abluções são importantes nos cultos, têm radicada centralidade na higiene, desempenham importante papel no consumo de um bem - a água. A água como bem, isso é já outro aspecto que merece a atenção do economista e do político. A água na arte, mormente nas artes ditas plásticas e na música, mas também na prosa e no verso - e aqui nos deparamos novamente com o poeta, que invocamos logo nas primeiras linhas desta reflexão. A água tem papel medianeiro e simbólico importante nas religiões, como acima lembramos; o pavilhão da Santa Sé na Expo de Lisboa era precisamente dedicado à água (baptismo, bênção, lava-pés...) e à sua importância ritual e sacramental. Não é, pois, da água do poeta, do químico, do físico, do sacerdote ou de tantos outros, 
uns aqui mencionados, outros não chamados a capítulo mas igualmente dignos de menção, tais como os engenheiros hidráulicos ou os pescadores, não é pois desta água ou destas águas que falaremos. É da água como princípio terapêutico e do seu uso ético que tentaremos dizer algo, de forma breve, como deve ser, por respeito ao eventual leitor e aos autores que nesta publicação deixam o seu contributo; e muito incompleta e superficial, por deficiência e incapacidade própria.

\section{Lavar, tratar?}

A forma tradicional, hoje ainda observada, de iniciar o tratamento de uma abrasão, ferida, solução de continuidade da pele consiste em lavar, com a água mais pura disponível, a lesão do revestimento cutâneo. Desde tempos muito recuados, certamente anteriores aos primeiros documentos épicos ainda existentes, que se lavaram as feridas, como primeira medida do seu tratamento; só depois se recorria a medidas de natureza química (aplicação local das mais variadas substâncias, alegadamente hemostáticas ou cicatrizantes) ou física (contenção, pressão, isolamento do meio ambiente). Não há dúvida que, ao eliminar a poluição e contaminação da ferida com terra, têxteis (roupa), produtos vegetais, etc., a simples lavagem terá evitado incontáveis possibilidades de infecção e, certamente, numerosíssimas mortes.

Mãos carinhosas e atentas de mães consumidas pelo medo do desconhecido terão, sem dúvida, aplicado panos molhados na testa de infantes febris ou mesmo mergulhado os seus corpos escaldantes em fresca água da fonte - uma técnica ainda hoje considerada útil e recomendada como manobra antipirética. Entorses, inflamações das partes moles ou osteoarticulares, as mais variadas dermatoses, desde banais dermatites atópicas até à ominosa lepra, constituem um longo cortejo de situações patológicas em que a água foi considerada como soberana indicação terapêutica, reunindo na sua cristalina simplicidade a eficácia de um remédio com a aura mágica de um meio de purificação, de lavagem do mal.

Dois exemplos vêm logo à mente. Um, o de Afonso Henriques a tentar recuperar da lesada perna direita, fracturada no fatídico "infortúnio do Rei", como delicadamente chamou o cronista ao desastre de Badajoz, banhando-se nas sulfurosas águas de S. Pedro do Sul. Apesar da esperança depositada nas virtudes curativas das águas de Alafões, e da demorada convalescença (Setembro a Novembro de 1169), é sabido que o resultado clínico não foi satisfatório, ficando o Rei menos capaz de montar a cavalo, provavelmente coxo e diminuído como figura e imagem de poder, que passou a partilhar com seu filho Sancho. O outro exemplo é-nos relatado por João (9, 1-41): o cego de nascimento, 
a quem Jesus unge os olhos com lama, é pelo Mestre enviado à distante Piscina de Siloé, para que ali se pudesse lavar. Ele assim fez e regressou curado. A lavagem, a purificação só tinha valor simbólico, mas era necessária para que se manifestasse o prodígio operado pelo Senhor.

É esta carga simbólica, conscientemente aceite ou placidamente ignorada, que têm outros rituais ligados à imersão na água, desde os baptismos praticados por algumas denominações cristãs (p. ex. no rio Jordão) até aos banhos de mar do primeiro dia do ano ou do dia de S. Bartolomeu: o que se procura é limpeza do ser total, purificação, remoção de máculas, promessa de futura felicidade, através da fruição de uma saúde de elevada qualidade.

E a água ingerida? Dado o reconhecimento universal da indispensabilidade de um regular aporte de água para a sobrevivência, não surpreende que à ingestão de água tenham sido atribuídas qualidades e virtudes terapêuticas. Neste sentido, ainda hoje, quando alguém se sente mal ou aparenta estar em risco de desfalecer, logo surgem as bem intencionadas propostas e ofertas de um fresco e reanimador copo de água. Nestas circunstâncias, o cuidado e interesse revelados pelo aquífero cireneu são, certamente, bem mais capazes de confortar e animar o paciente do que a água oferecida.

Não obstante, há importantes e frequentes circunstâncias em que a ingestão de água adquire primordial relevo terapêutico. Referimo-nos, claro está, às situações de hipertermia, hipersudação, diarreia abundante, todas elas conducentes a desidratação e nas quais a administração de água (e de sais eventualmente espoliados, como acontece nas diarreias) permite alcançar a almejada cura. Não olvidemos, todavia, que o excesso de ingestão de água pode provocar graves desequilíbrios hidroelectrolíticos, configurando uma verdadeira intoxicação aquosa (raramente observada na clínica, quase sempre apanágio de doentes mentais, incapazes de observar a justa medida nas suas necessidades de líquidos, mas menos rara em doentes hospitalizados e sujeitos a uma demasiado entusiástica terapia intravenosa com soluções parenterais volumosas, vulgarmente designadas por soros).

Aágua não é um elemento, no significado químico da palavra, como de resto nenhum dos componentes da tetralogia clássica assume forma elementar. Mas tal como o fogo, a terra e o ar, a água adquire um papel fundamental nas tradições religiosas, servindo de ponte, símbolo e veículo entre o imanente humano e aquilo que o transcende, o poder do divino, que salva e cura. Cura os males do espírito, liberta do mal, mas não despreza aquele bem a que chamamos saúde e que sempre foi considerado como importante peça integrante da felicidade terrena. Assim, a salvação e a cura vêm do divino, mas não dispensam mediação material, que tantas vezes dependerá, como na piscina de Siloé, da humilde água. 


\section{A força curativa da natureza}

Falamos, até aqui, do tratamento pela água, ou seja, da hidroterapia, na qual se recorre a uma qualquer água, que até pode vir da rede pública. Claro que alguns indivíduos, industriosos e não imunes aos poderes encantatórios do dinheiro, cedo entreviram a possibilidade de tornar mais atraentes as instalações para banhos, modificando a temperatura da água, adicionando massagens, aplicação de lamas, jactos, pulverizações, etc. e explorando economicamente tais instalações. Como no tempo dos romanos ou na Renascença, tais banhos gozam de imensa popularidade, adquiriram exóticas designações (SPA, Welness Centre) e contribuem, certamente, para o lazer e o bem estar de inúmeros cidadãos estressados pelos ritmos e exigências do seu viver quotidiano. Mas embora a visita a estabelecimentos deste tipo possa contribuir para a sensação daquele bem estar que é base fundamental para a definição oficial de saúde (da Organização Mundial para a Saúde), não se pode dizer que esta hidroterapia (ou a sua derivada, a talassoterapia, praticada com recurso à água do mar) constitua, propriamente, uma forma de tratamento pela água, uma vez que são outros factores, ancilares embora, os mais relevantes neste contexto - calor, saturação de humidade na atmosfera, fisioterapia, manipulação, massagem, silêncio ou suave melodia, etc.

Desde tempos remotos, todavia, se atribuíram a certas águas propriedades curativas, dependentes ou não da divindade. Pelo menos a partir da Idade Média se começou a instalar o conceito de que essas águas tinham indicações seguras em afecções específicas - prefigurando o que hoje se chama crenoterapia, ou tratamento termal ou terapia com águas minero-medicinais (em parlança legal, águas minerais naturais).

No longo caminho percorrido pela crenoterapia não devemos, talvez, recuar até à antiguidade clássica, já que os gregos e romanos, dedicados e entusiásticos utilizadores dos banhos, não atribuíam, em geral, virtudes especiais a águas geograficamente localizadas, isto é, podem considerar-se adeptos da hidroterapia, mas não da crenoterapia. A Renascença, com o seu eruptivo interesse pela natureza e pelo corpo humano, distinguiu já águas santas ou curadoras; não esqueçamos o gesto iniciático da Rainha D. Leonor, ao criar o primeiro Hospital Termal do mundo, o das "suas"Caldas. Foi preciso, porém, esperar pelo século XVIII para Francisco da Fonseca Henriques, o famoso Dr. Mirandela, elaborar o Arquipélago Medicinal, no qual fez o primeiro levantamento hidrológico nacional. E é só no século XX que surgem algumas, raras, tentativas de investigação científica acerca dos efeitos fisiológicos e terapêuticos das águas minerais, alimentadas pela criação de Institutos de 
Hidrologia nas três maiores Faculdades de Medicina portuguesas e pelo reconhecimento, por parte da Ordem dos Médicos, da competência em Hidrologia Médica (que pode ser obtida por quem tenha uma especialidade, aprovação no curso de um dos Institutos de Hidrologia e estágio em estância termal).A análise química veio comprovar o que os sentidos já tinham ensinado: estas águas são diferentes, têm características que as distinguem de tantas outras, suas irmãs anónimas. Contêm quantidades apreciáveis de sulfatos, silicatos, fluoretos, sulfuretos, bicarbonatos, cálcio, sódio, magnésio, etc.; brotam da terra a baixa temperatura ou, pelo contrário, escaldam (e por isso se designam por Caldas); algumas ostentam um certo grau de radioactividade, outras são gasocarbónicas. As respectivas fontes são o centro de estâncias termais - o termo tem origem no facto de as mais famosas, na antiguidade, terem sido as que brotam da terra a elevada temperatura - e multidões de doentes, convalescentes ou indivíduos sãos que procuram manter a saúde deslocam-se a estes locais de esperança. São sobretudo doentes crónicos, afligidos por males de baixa intensidade mas altamente incómodos e interferindo com a vida quotidiana os que passam alguns dias (a tradição prescreve uma ou duas semanas) nas termas. Reumatismos, afecções respiratórias (sinusites, bronquites, mas também asma), alterações do trânsito intestinal (colites, cólon irritável), dermatoses várias contribuem para mais de três quartos das motivações para a crenoterapia.

As águas medicinais são administradas nas mais variadas técnicas e formas, como é sabido: bebidas, claro, mas também usadas para banhos de imersão, duches variados (escossez, Vichy, subaquático, etc.), aplicação de lamas ou peloides, inalação, irrigação, enteróclise... Em muitas termas, a preocupação com a conquista de mercado levou à adopção de formas de hidroterapia que se assemelham às praticadas em hotéis e centros de bem-estar, delas só se distinguindo por neste caso se recorrer à água mineral própria da estância termal. Os críticos puristas censuram esta atitude, já que a noção de tratamento, própria das termas, se abastarda e dilui com a degradação da água curativa em propiciadora de bem-estar e relaxamento. Todavia, pode e deve entender-se essa atitude, alargadora das razões que levam à frequência de uma estância termal como justificada quer pela evolução das expectativas do público (que, familiarizado com as técnicas de hidroterapia a que recorre em spas, espera poder gozar da mesma oferta na estância que apresenta a mais valia de um efeito terapêutico da sua água), quer pelo enquadramento legal. De facto, o Decreto-Lei 142/2004, de 11 de Junho, define como actividades próprias das estâncias termais o tratamento termal (a realizar com as técnicas termais, ou seja com os meios para aplicação da água), o recurso a técnicas complementares (p. ex. massagens, cinesiterapia) e a prestação de serviços de bem-estar 
termal. Significa isto que, para além da vertente terapêutica (crenoterapia) e de prevenção da doença ou reabilitação de patologias anteriores, a lei prevê a prestação de serviços que contribuem para o bem-estar e um incremento da qualidade de vida.

A outra acusação implícita na crítica purista ou fundamentalista à inclusão da promoção do bem-estar nas actividades termais é a de que essa atitude só foi tomada por motivos económicos, para aumentar o número de aquistas e recrutar pessoas jovens (tradicionalmente, a clientela maioritária das termas ultrapassa os 65 anos), bem como para evitar um dos graves males da gestão económica das estâncias, que é o da marcada sazonalidade da sua actividade. Talvez haja alguma verdade nesta crítica, mas é óbvio que não é por esta via que se obterá a almejada rentabilidade dos estabelecimentos termais - não se pode comparar o ingresso resultante de estadias de duas semanas com o que provém de um fim de semana; além disso, como é sabido, o aquista que procura alívio para os seus males (em geral crónicos) tende a repetir o tratamento ao menos uma vez por ano, enquanto que o turista que recorre ao breve período de bem-estar desconhece esta fidelização, preferindo experimentar novos ambientes.

As termas foram em toda a Europa, especialmente nos séculos XVIII e XIX, incontornáveis centros da vida social e política. Bath, Karlsbad, Marienbad, Evian, Baden - Baden, Vidago, Curia são exemplos sonantes: a Europa (ou pelo menos os que contavam na Europa) ia a banhos. Membros de casas reais, políticos, banqueiros, militares, escritores, mas também novos ricos, industriais, comerciantes abastados, deslocavam-se com suas famílias ou séquitos (secretários, criados, amas, guarda-costas, cocheiros) aos luxuosos palaces cujas instalações magníficas ajudavam a esquecer os rigores do tratamento termal. Os remediados tinham à sua disposição as pensões e os quartos alugados e divertiam-se com o espectáculo gratuito de ver passear e conversar, nos parques, os grandes do mundo, muitas vezes provindos de outros países (Baden - Baden, p. ex., era de frequência obrigatória para a elite russa). E ainda havia concertos, ópera, casino, bailes, corridas (actividades hoje resumidas ao que se anuncia nos hotéis sob a estranha designação de "animação").

As guerras do século XX, o seu cortejo de misérias e as profundas transformações sociais ocorridas obrigaram a marcadas alterações e ameaçaram a própria sobrevivência das termas. Algumas, não poucas, estâncias, fecharam ou decaíram em modesto pouso de férias, mas muitas resistiram e souberam renovar a sua imagem, mais perigosamente atingida pela atitude de dúvida de médicos e cientistas do que pela evolução social verificada. De facto, há que reconhece-lo, a dúvida sistemática, quando não a derisão e o sarcasmo, atingem seriamente o termalismo. Segundo uma corrente numerosa e por 
vezes aguerrida, o termalismo não teria base científica, as curas ou melhorias atribuídas à água são ilusórias ou devem-se a outros factores, as águas actuam, quando muito, como um placebo, isto é, são farmacologicamente inertes, mas exercem efeitos através da psique. Não faltam, porém, médicos a defender o termalismo e a garantir a veracidade das melhorias e até curas registadas em milhares e milhares de casos.

Esta disputa é, na realidade, uma quaestio vexata, para a qual se não entrevê uma resposta satisfatória. É certo que não há provas convincentes, cientificamente inatacáveis, do poder terapêutico destas águas; para tal seria necessário comparar grupos homogéneos de doentes, postos exactamente nas mesmas condições (alojamento, dieta, exercício), excepto no que diz respeito ao tratamento, que num grupo consistiria na administração da água em estudo e no outro de uma água não minero-medicinal. O estudo teria de decorrer sob dupla ocultação, isto é, nem os médicos avaliadores nem os sujeitos do ensaio saberiam se estavam a tomar a água termal ou a água não termal. Além disso, o número de sujeitos teria de ser elevado e os critérios de melhora ou cura muito objectivos, com recurso a métodos analíticos sofisticados.

Não existem estudos deste tipo, nem se pode esperar que venham a ser realizados, tantas são as questões práticas e os escolhos administrativos e até legais que se opõem à sua concretização. Quem seriam os promotores e organizadores dos ensaios? Quem pagaria as muito consideráveis somas necessárias para a sua execução? Como seria possível ocultar dos participantes no ensaio a natureza da água que iriam tomar, se as características da água mineral (cheiro, gosto) claramente a distinguiriam da água comum? Seria razoável discriminar entre os dois grupos, privando um do tratamento que teria motivado a sua deslocação à estância termal?

Não há pois provas da eficácia terapêutica das águas minerais; mas é necessário sublinhar que tal asserção não autoriza a que se conclua que as águas são ineficazes: a ausência de prova de eficácia não é sinónima de prova de ausência de eficácia, como há muito nos lembram os especialistas dos ensaios clínicos. Não se pode ficar indiferente, por outro lado, aos argumentos invocados pelos paladinos das águas: como explicar a popularidade destas terapias, através dos séculos e da geografia? Como interpretar as declarações espontâneas de tantos milhares de beneficiados? Como duvidar do testemunho de multidões que continuam a acorrer às termas, com considerável dispêndio e sacrifício de tempo (só em Portugal são cerca de 100.000/ano)? Como explicar que a Alemanha, que dispõe de médicos com formação científica e capacidade crítica, seja o país da Europa com maior frequência termal, em percentagem da população? 
Os cépticos dizem que gastar dinheiro e tempo é um meio consagrado para depositar ofertas no altar das divindades da saúde e lembram os asklepions dedicados a Apolo e a Higeia; atribuem as melhorias registadas ao descanso, aos ares puros, à mudança de hábitos, à dieta, ao convívio social (que proporciona novos conhecimentos, novas amizades). Mas ao adoptar esta linha de argumentação, aceitam o benefício do tratamento termal, limitando-se a excluir a água como agente causal desse mesmo benefício - ou seja, não negam o carácter benéfico do tratamento termal.

Na impossibilidade de resolver a questão e de dirimir a disputa entre cépticos e crentes, parece adequado concluir que a crenoterapia está viva e continuará a melhorar a vida de muita gente, seja através de intervenção no metabolismo e no sistema imunitário, ou da mais subtil modificação, de misteriosas consequências, da actividade cerebral, a que imprecisa e um pouco grosseiramente chamamos expectativas, esperanças, convicções, sentir o corpo e o seu lugar no cosmos.

\section{E a ética?}

Já para aqui foi chamada a ética, a propósito da questão da simultaneamente proclamada e negada eficácia da crenoterapia. Mas é muitíssimo mais abrangente a problemática de cariz ético, no que respeita à água. Em primeiro lugar é necessário sublinhar que apenas 3\% da água existente no mundo é potável (“doce") e que cerca de 2/3 desta água não está disponível para uso humano, por se apresentar na forma sólida (glaciares, gelo polar e icebergs). Quer isto dizer que a crescente população do globo só pode recorrer, para todos os usos que dá à água "doce", a cerca de 1\% do total de água presente no globo. Ora, sendo conhecida a indispensabilidade da água para a vida e actividade do Homem, a sua escassez é um factor limitante para o desenvolvimento sustentável da humanidade. Que a água é um bem escasso, disso já ninguém duvida; e que essa escassez se distribui de forma muito irregular pelo globo é uma evidência que, como tal, não carece de demonstração: há regiões que sofrem secas apocalípticas (o Corno de África vem-nos logo à ideia, com o seu terrível cortejo de fome e violência, nascidas da falta de água) e outras, como a Europa, em que o fornecimento de água potável, de boa qualidade, a toda a população se afigura como direito adquirido e parte integrante do normal quotidiano.

Acresce que uma parte considerável da população (cerca de 40\%) recorre a águas com origem transfronteiriça, isto é, que provêm de outros países. Este facto desempenha importante papel geopolítico, pois pode dar facilmente origem a conflitos e a chantagem, só podendo conseguir-se uma gestão equitativa dos recursos através de tratados internacionais. Em Portugal, como se sabe, a 
maioria dos fluxos hídricos provem de Espanha, e só a existência de um tratado e de órgãos de regulação conjunta dos recursos pode evitar, ou pelo menos suavizar, disputas sobre a gestão das reservas, em época de seca.

Outro ponto a considerar é o da tarefa de produção de energia que atribuímos aos cursos de água. As instalações hidroeléctricas, por vezes faraónicas, geram energia limpa, sem dúvida; mas, para avaliarmos da justeza destas iniciativas, temos de ter presentes aquilo a que poderíamos chamar os seus danos colaterais: alterações marcadas da paisagem, enorme movimentações de terras, destruição de habitats naturais (fauna, flora, humanos), alterações climáticas, riscos de eutrofização dos grandes volumes da água retida pelas barragens, etc.

Também as incomensuráveis massas de água representadas pelos gelos polares e pelos oceanos se encontram em risco de graves alterações: o aquecimento global, ao provocar o derretimento dos gelos, conduzirá a uma elevação do nível do mar e à consequente inundação de ilhas e faixas costeiras baixas; a poluição trará (e já traz, em algumas zonas) disrupções nos ecossistemas fitozoológicos, com desaparecimento de espécies e proliferação de organismos eventualmente danosos ou tóxicos; e a pesca excessiva, não poupadora de peixes e crustáceos juvenis ou em risco, constitui uma ameaça não desprezável.

Perante este quadro sombrio, que fazer? A reflexão ética, que deve presidir à tomada de decisões orientadoras do agir, parte de um pressuposto evidente: toda a problemática elencada tem a sua origem no Homem, é pois ao Homem que cumpre a tarefa de encontrar as soluções que permitam a sua subsistência num mundo equilibrado e justo. A sua responsabilidade não pode ser negada nem menorizada: a nós, à espécie humana, pertence a tomada de responsabilidade pelas nossas acções em relação à manutenção do bem precioso e indispensável que é a água. E como insistentemente nos lembra o filósofo Hans Jonas, essa responsabilidade tem de ser assumida também em relação às gerações futuras, que certamente não têm direitos, pois ainda não existem, mas às quais nos liga o compromisso irrevogável de lhes deixar como herança um mundo habitável, que antes de mais será um mundo com recursos hídricos suficientes. Parafraseando o imperativo categórico kantiano, Jonas insistiu na necessidade de cada um de nós agir, em relação ao ambiente, como se o nosso proceder pudesse ser considerado lei universal, tendo em conta as gerações futuras.

Tal desiderato só pode ser atingido se cada um de nós aceitar essa responsabilidade e governar o seu agir de acordo com as normas que garantam a preservação da nossa comum herança natural. No que respeita à água, o que compete a cada indivíduo é simples e faz parte de uma cartilha difundida por muitas instituições governamentais (ou não): poupar, reciclar, não poluir. Aos indivíduos e às escolas cabe a missão de ensinar crianças e jovens a 
respeitar as mesmas regras; as autarquias e os governos têm uma esfera de acção bem mais vasta, na administração e preservação dos recursos, na adopção das medidas correctas, na proibição de iniciativas prejudiciais. A proliferação de piscinas, relvados e campos de golfe, p. ex., não deve ser encarada como medida sempre louvável, de reflexos positivos no bem-estar e no turismo, se não for devidamente enquadrada (garantia de não afectação dos níveis freáticos, recurso ao reaproveitamento de águas residuais, adopção de técnicas de irrigação que evitem clamorosos desperdícios, etc).

Poder-se-á objectar que estes procedimentos, mesmo se postos em prática por grande parte da população, não resultarão em benefício dos que vivem em regiões mais carenciadas, menos desenvolvidas, mais pobres, em que a escassez de água é apenas uma conta de um rosário de amarguras, infortúnio e injustiça. Mas não é bem assim, em primeiro lugar por num mundo globalizado e multicultural se registar a tendência para mimetização e contágio; ou seja, se os países ditos desenvolvidos adoptarem uma agenda correcta, no que concerne ao ambiente e, no caso de que nos ocupamos, à água, provavelmente os procedimentos correctos constantes dessa agenda serão progressivamente aceites e postos em prática nas zonas mais desfavorecidas. Em segundo lugar, a solidariedade ontológica leva organizações, grupos e governos a prestar ajuda significativa às populações de áreas com graves problemas no sector hídrico: medidas tão simples como a construção de cisternas para arrecadação da água pluvial ou a perfuração de poços eficientes; ou, pelo contrário, onerosas e complicadas como a regularização de rios, a dessalinização de água do mar, o tratamento e reaproveitamento de águas residuais - constituem significativa contribuição para uma melhoria das condições de vida e da saúde das populações atingidas.

Todavia, é preciso ter em conta que todas as medidas de ordem prática que venham a ser tomadas, com o fito de conservar e usar com prudência as escassas reservas hídricas, são de natureza utilitária (poupamos água para termos água) mas têm igualmente cariz ético não utilitarista, obedecendo aos grandes princípios que devem orientar o agir: poupamos água por esse ser um dever inalienável e uma obrigação perante outros, contemporâneos ou futuros.

Deste modo, as nossas atitudes inserem-se de forma adequada no que poderíamos chamar uma ecoética responsável: estamos conscientes da riqueza do meio que nos rodeia, das benesses ambientais de que ainda gozamos, e que temos de preservar, respeitar e transmitir às futuras gerações. Este é um pacto solene que nos compromete e eleva.

Numa declaração prestada a um jornalista do National Geographic Magazine, um tuaregue anónimo resumiu sabiamente a questão: a água não é 
indispensável à vida, a água é a própria vida. Ora, nenhuma corrente ética negará o direito à vida, que é apanágio de toda a pessoa humana; sendo assim, não se pode negar o direito de qualquer pessoa a ter acesso à água, e água de boa qualidade. Respeitar esse direito, fomentar a sua concretização é, pois, tarefa universal.

\section{A concluir}

Aágua, fonte de vida, elemento indispensável à sobrevivência, inspiradora de poetas e pintores, murmurando seus segredos ao ouvido dos músicos, deixando-se analisar, pesquisar e medir pelos cientistas, dócil colaboradora do Homem na produção de alimentos ou de energia, sempre pronta a estancar a sede, a cobrir de verde e de alegres cores a terra de burel, indispensável aos cultos e à celebração, a água é um bem precioso, que a evolução da humanidade põe em risco. Além disso, tem indiscutível valia terapêutica, e tem sido aproveitada pela argúcia humana como cura, real ou imaginária, para muitas maleitas.

Este bem em risco exige de todos coerentes atitudes e decididas intervenções, para que se não torne mais escasso ainda e para que todos possam ter acesso à sua fruição. Poupar a água, não a poluir, re-utilizá-la, ensinar a respeitar - e a amar - a água é tarefa universal e um imperativo ético irrecusável.

\section{Nota}

Chamo a atenção para as obras multi-autorais referidas, na breve lista bibliográfica que se segue e que tratam de várias perspectivas do tema.

\section{Bibliografia}

Araújo, J., Carvalho, A.S., Renaud, M. - "A água e a ética”. In Malcata, F.X. (coord.), Água, um desafio sem espaço nem tempo. Universidade Católica Editora, Lisboa, 2009.

AAVV - À beira da água. Comissão de Coordenação e Desenvolvimento Regional do Centro, Coimbra, s.d..

AAVV - Água, um desafio sem espaço nem tempo. Universidade Católica Editora, Lisboa, 2009.

Bouguerra, M. - As batalhas da água. Por um bem comum da humanidade. Campo das Letras, Porto, 2005.

Küng, H. - Projecto para uma ética mundial. Instituto Piaget, Lisboa, 1990. 
Selborne, L. - A ética do uso da água doce: um levantamento, Publicações Unesco, Brasília, 2001.

Teixeira, F. - "Água, fonte de vida" - In AAVV, À beira da água. Comissão de Coordenação e Desenvolvimento Regional do Centro, Coimbra, s.d..

Recebido: 05/12/11

Aceite: 24/04/12 